\title{
La política exterior de Bolivia en tiempos de Evo Morales Ayma
}

\author{
Bolivian foreign policy during Evo Morales Ayma' administration \\ Natalia Ceppi ${ }^{* *}$ \\ Universidad Nacional de Rosario, Rosario de Santa Fe, Argentina
}

Recibido: 27 de noviembre de 2013. Aprobado: 7 de abril de 2014.

\begin{abstract}
Resumen
El presente trabajo analiza la política exterior boliviana a partir de la llegada de Evo Morales, considerando la diplomacia desplegada en el ámbito de Naciones Unidas y las relaciones bilaterales más destacadas en el período 2006-2013. Se parte de la idea de que las transformaciones experimentadas en el ámbito doméstico - tanto en los postulados ideológicos como en materia político-económica- han repercutido en el proceso de ajuste y reestructuración que atraviesa la agenda externa del país. En este sentido, se afirma que en tiempos de Evo, la política exterior se diferencia de los gobiernos anteriores en tres puntos principales: los principios y objetivos que la sustentan; la valoración otorgada a los espacios multilaterales como foros de debate y discusión; y los vínculos de Estado a Estado.
\end{abstract}

Palabras claves: Bolivia, política exterior, Evo Morales

\footnotetext{
Una versión preliminar de las líneas de investigación que aquí se presentan fueron abordadas en el marco de la obra colectiva América del Sur en los comienzos del nuevo milenio: entre la continuidad y el cambio, que forma parte del Proyecto de Investigación "De la vieja a la nueva democracia en Venezuela: entre la continuidad y el cambio fundacional", dirigido por el Dr. Santiago Leiras y financiado por el Programa UBACYT de Investigación Científica y Tecnológica de la Universidad de Buenos Aires (UBA) para el período 2012-2015. Al momento de escribir este artículo, dicha obra se encuentra en prensa.

** Universidad Nacional de Rosario (UNR), Santa Fe, Argentina. Consejo Nacional de Investigaciones Científicas y Técnicas (CONICET). Correo electrónico: nataliaceppi@yahoo.com.ar
} 


\begin{abstract}
This paper analyzes Bolivian foreign policy since Evo Morales' arrival, considering the diplomacy displayed in relationship to the United Nations, as well as the most prominent bilateral relations during the period of 2006-2013. The article argues that the transformations experienced in the domestic arena -in ideological postulates and in political and economic matters - have affected the process of adjustment and restructuring of the country's foreign agenda. In this sense, it affirms that in Evo's time, the foreign policy of Bolivia clearly differs from previous governments in three areas: the principles and objectives that support it; the importance of multilateral spaces for debate and discussion, and the relations from State to State.
\end{abstract}

Keywords: Bolivia, foreign policy, Evo Morales

\title{
Introducción
}

La victoria de Evo Morales Ayma en las elecciones presidenciales del 18 de diciembre de 2005, a través del Movimiento al Socialismo (MAS), significó un punto de inflexión en la historia socio-política de Bolivia. Tras dos décadas de alternancia en el poder, los partidos políticos tradicionales quedaron relegados frente a un líder indígena y sindical, defensor de los derechos de los excluidos y que esgrime la necesidad de establecer un quiebre con el pasado. Desde la óptica del gobierno nacional, este proceso implica llevar adelante la "refundación del Estado-nación", con miras a redefinir no solo los vínculos del Estado con la economía y la sociedad, sino también el relacionamiento externo del país.

Contemplando ambos planos, es decir, el doméstico y el externo, la administración Morales lanzó el 16 de junio de 2006 el Plan Nacional de Desarrollo, entendido como una estrategia de acción global, cuyas directrices apuntan a consolidar "una Bolivia digna, soberana, productiva y democrática para vivir bien". A nivel interno, el nacimiento de una nueva Constitución Política en enero de 2009 -más representativa de la diversidad cultural nacional-; la política de nacionalizaciones, especialmente de los hidrocarburos, y la implementación de medidas sociales para combatir la pobreza y la marginalidad, son los ejemplos más representativos del proceso de renovación - en ocasiones tenso y conflictivo- en el cual está inserto el Estado andino. 
Por su parte, desde 2006 la política exterior ha mantenido como temas de agenda ciertos ejes que podrían considerarse históricos, a saber, el respeto por la democracia y los derechos humanos, la reivindicación marítima, la lucha contra el narcotráfico, la integración económica y la cooperación transfronteriza, entre otros. No obstante, ha atravesado mutaciones significativas, ya que ha sido rediseñada en cuanto a los principios y objetivos que la sustentan; la importancia asignada a los espacios multilaterales como ámbitos de diálogo y planteo de demandas y las relaciones bilaterales establecidas.

En base a lo mencionado, el presente trabajo se orienta a responder los siguientes interrogantes: ¿cuáles son los principales objetivos planteados por la gestión del MAS en materia de política exterior? ¿Sobre qué temas, que son parte de la agenda nacional, Evo Morales ha focalizado el debate en el ámbito de Naciones Unidas? Y, por último, ¿cómo han evolucionado las relaciones bilaterales más destacadas desde 2006 hasta la actualidad? En este punto se consideran tres ejes; en primer lugar, aquellos que vislumbran un mayor fortalecimiento, Venezuela, Argentina y Brasil; en segundo lugar, los que representan los "nuevos socios" en la agenda de política exterior - China e Irán-y, finalmente, los que demuestran claros signos de conflictividad, tales como Estados Unidos y Chile ${ }^{1}$.

\section{¿Una política exterior renovada?}

Tal como plantea Mayorga (2008), desde principios de la década del 2000, la política boliviana se enmarca en un proceso de transición estatal donde se han puesto en juego dimensiones como la definición de un nuevo modelo de desarrollo, la descentralización política del país, el reconocimiento de los derechos colectivos de las comunidades indígenas y las pautas de participación y representación política democrática (pp. 21-22). Con la asunción de Evo Morales, estas dimensiones cobraron mayor protagonismo en la agenda política, y en consonancia con la idea de establecer "un quiebre con el pasado", el gobierno nacional ha impulsado un conjunto de políticas orientadas a la (re)construcción de un Estado plurinacional, comunitario y protagonista de su propio desarrollo (Plan Nacional de Desarrollo, 2006). Entre las más sobresalientes se encuentran: a) la nacionalización de industrias diversas, como hidrocarburos, electricidad, agua y saneamiento, telecomunicaciones, etc.; b) la redacción de una nueva Carta Magna, aprobada por referéndum en enero de 2009, que reconoce las demandas indígenas y campesinas y los reclamos autonómicos y c) el lanzamiento de bonos sociales - Juancito Pinto, Juana

\footnotetext{
Mediante la selección de estos casos, se pretende ilustrar cuáles han sido los vínculos bilaterales más representativos y qué transformaciones han atravesado los mismos al momento de evaluar el proceso de cambio de la política exterior boliviana a partir de 2006.
} 
Azurduy y Renta Dignidad, por ejemplo- destinados a mejorar la calidad de vida de las poblaciones más vulnerables, buscando reducir los márgenes de exclusión y desigualdad.

Debido a que el proceso de "refundación del Estado-nación" no se agota en el ámbito interno, desde la llegada del masismo la política exterior ha experimentado mutaciones significativas ${ }^{2}$. En esta dirección, es importante tener en consideración los aportes de Lasagna (1995), quien además de revalorizar a la política interna en tanto factor explicativo - aunque no exclusivo- del comportamiento externo de un Estado, subraya que la política exterior se inserta en un esquema cíclico de continuidad y cambio (pp. 388-389). Siguiendo con las ideas del autor, el cambio es un continuum, conformado tanto por cambios "macros" como "micros", cuya existencia responde a los condicionantes del contexto internacional, pero fundamentalmente a la política doméstica, el Estado, los procesos decisorios y la sociedad, entre otros ${ }^{3}$. De esta manera, los constreñimientos externos, la coyuntura regional, los postulados ideológicos y los cambios en la agenda doméstica permiten explicar por qué la política exterior de Morales se distancia de aquella llevada adelante por gestiones anteriores.

Cabe recordar que a mediados de la década del 1980, Bolivia atravesaba una profunda crisis económica, política y social. La inflación crecía a pasos agigantados, el Producto Interno Bruto (PIB) experimentaba una caía estrepitosa y el país no contaba con financiamiento internacional ante la cesación de pagos de los intereses de la deuda (Sanjinés, 2007, p. 78). Ante esto, el entonces presidente Víctor Paz Estenssoro (1985-1989) dispuso a través del Decreto 21.060 del 29 de agosto de 1985, la puesta en marcha de la denominada "Nueva Política Económica" que sustentó las medidas neoliberales propias de la época. En este contexto, la política exterior tuvo un papel auxiliar en la implemen-

2 En este trabajo, la política exterior es entendida desde una acepción "amplia" y tal como expresa Lasagna (1995), refiere a "aquel área de actividad gubernamental que es concebida como las relaciones entre el Estado y otros actores, particularmente otros Estados (pero no exclusivamente), en el sistema internacional” (p. 389). Así, la política exterior es una actividad pública, que comprende un conjunto de decisiones que los gobiernos elaboran frente a determinadas situaciones para alcanzar objetivos y/o satisfacer necesidades en las vinculaciones que se establecen a nivel de Estado-Estado, o con otros actores en el escenario internacional. Este conjunto de decisiones es producto de una relación sinérgica entre los condicionantes exógenos (las características del sistema regional e internacional) y los domésticos (los factores económicos, culturales, históricos, políticos, etc. y los diversos actores que son parte del contexto nacional). Ambas categorías de factores -internos y externos- "no están en competencia, sino que se complementan" [en realidad] es una relación de "doble vía" (Van Klaveren, 1992, p. 178).

3 Lasagna (1995) identifica tres niveles de cambio: la reestructuración es un cambio rápido que intenta modificar los lineamientos básicos de la política exterior; la reforma es un proceso lento, incremental y referido a los aspectos parciales de la política exterior y por último, el ajuste, que conlleva pequeñas alteraciones en los lineamientos de proyección externa del país, siendo este el nivel de cambio menos intenso (pp. 393-394).

\section{Si Somos Americanos. Revista de Estudios Transfronterizos}


tación de dichas medidas, debido a que en el afán de canalizar recursos financieros, el accionar externo se orientó al acatamiento irrestricto de los postulados del Consenso de Washington, promovidos por Estados Unidos y los organismos internacionales de crédito (Kafka, 1995). A esta situación debe agregarse otro factor que fortalecía la dependencia de Bolivia con respecto a Estados Unidos: la práctica de certificación/descertificación, según el nivel de cooperación en la lucha contra las drogas en América del Sur. Tal como plantea Tokatlián (1997), "Estados Unidos se auto-adjudicó el derecho a evaluar quiénes enfrentaban el asunto de las drogas, cómo lo hacían y de qué modo lo debían hacer" (p. 6). Por ello, si Bolivia - al igual que Colombia, Perú y Ecuador- era descertificada en este cometido, ponía en riesgo su permanencia dentro del sistema de preferencias comerciales contempladas en el Acta de Preferencias Arancelarias Andinas (ATPA, en inglés) firmada en 1991 (Tokatlián, 1997, p. 8).

La instauración de los programas de ajustes estructurales del Fondo Monetario Internacional (FMI) y el Banco Mundial (BM), y el "temor" a ser descertificado por Estados Unidos, generaron que la política exterior boliviana de los años 90 e inicios del siglo XXI estuviera fuertemente influenciada por el factor económico y denotara una escasa diversificación de vinculaciones. Con el advenimiento de la administración Morales, la lógica de proyección externa fue adquiriendo nuevos matices, marcando una diferencia con sus predecesores con respecto al espectro de relaciones político-económicas y el lugar asignado al componente ideológico (Mayorga y Rodríguez, 2010; Fernández, 2009). Como acontece con las políticas implementadas en el ámbito doméstico —indicadas en líneas anteriores-, la inserción internacional del país también se asienta en las nociones de "cambio" y "vivir bien" y se apoya discursivamente en tres ejes temáticos, a saber, indigenismo; anticapitalismo/anti-imperialismo y ambientalismo (Trejos, 2012, pp. 47-51). Así, en base a estas consideraciones, los principales pilares que sustentan la "refundación del Estado-nación" a nivel externo son"5:

4 De acuerdo al Plan Nacional de Desarrollo, el "vivir bien" es una propuesta de desarrollo propia de las culturas indígenas que postula una visión cosmocéntrica, relegando los contenidos etnocéntricos tradicionales del desarrollo (2006, p. 11).

5 Debido a que la formulación de la política exterior es potestad del Ejecutivo, es importante tener en consideración cómo se estructura el MAS, a los fines de entender los postulados ideológicos y los objetivos en materia de política exterior. Esta fuerza se nutre de los sindicatos cocaleros, los movimientos sociales del altiplano y los "remanentes radicales de los partidos izquierda que repiten pautas nacionalistas de los setentas" (Fernández, 2009, p. 1). El MAS no surgió como un partido, sino como un instrumento político de la Confederación Sindical Única de Trabajadores Campesinos de Bolivia (CSUTCB), pero con la intención de integrar el sistema político y ser un actor relevante del mismo (Machado, 2011, pp. 174-175). 
- La valoración de la soberanía y la identidad nacional y el rechazo abierto a la injerencia extranjera. La política exterior tiene que recuperar los márgenes de autonomía que fueron relegados en gobiernos anteriores.

- La promoción de esquemas de integración de corte más heterodoxo versus los modelos neoliberales. El neoliberalismo afectó el crecimiento nacional, limitó la inserción internacional del país y redujo la capacidad de gestión del Estado, beneficiando a intereses extranjeros.

- El fortalecimiento del rol del Estado en la explotación de los recursos naturales. El control del excedente derivado de su comercialización es en beneficio de la población boliviana en base al Vivir Bien.

- La diversificación de las relaciones internacionales económicas y políticas a fin de romper con el alineamiento a Estados Unidos. La vinculación externa del país con otros Estados debe orientarse en principios como la solidaridad, la complementariedad, la equidad y la reciprocidad, entre otros (Plan Nacional de Desarrollo, 2006, pp. 194-199).

De estos pilares mencionados, se desprende la idea que — desde la óptica del oficialismo - la redefinición de la política exterior representa no solo la "otra cara" del proceso de instauración de un "nuevo patrón de desarrollo", sino también una herramienta que lo impulsa (Plan Nacional de Desarrollo, 2006). En otras palabras, la política externa debe coadyuvar a la construcción de una sociedad donde el Estado debe cumplir el papel rector de la actividad económica y velar por el interés colectivo, contrarrestando - mediante la implementación de políticas multisectoriales - la desigualdad y la inequidad social. Ahora bien, ¿en qué espectro de vinculaciones y/o acciones es posible identificar este proceso de "metamorfosis" de la política exterior boliviana? Para dar respuesta a esta interrogante, es necesario hacer una distinción entre los planos multilateral y bilateral, con el fin de comprender más profusamente cuáles han sido los principales hechos y temas que marcaron la gestión externa del país, a partir de la victoria del proyecto masista.

6 Según el Plan Nacional de Desarrollo, se habla de "patrón de desarrollo" y no de "modelo de desarrollo", porque implica un proceso de construcción -económica, política y social- que no sigue prototipos preestablecidos o ya validados (2006, p. 15). 


\section{Naciones Unidas: derechos indígenas, agua potable y hoja de coca}

Desde su llegada al Palacio Quemado en 2006, Evo Morales ha llevado adelante una política activa en diferentes espacios multilaterales tanto a nivel regional como extraregional, siendo el caso de Naciones Unidas el más significativo. Por su condición de universalidad, dicha organización le permite al Primer Mandatario promulgar y defender a escala global cuestiones que son representativas de las demandas de gran parte de la sociedad boliviana y que están en relación con el proceso de "refundación del Estadonación". Sin dejar de reiterar su posición a favor de reformar la estructura de la organización, el presidente boliviano ha manifestado la importancia que esta reviste para la comunidad en su conjunto. En su discurso ante la Asamblea General, en 2011, sostuvo que:

este foro [posibilita] expresar lo que sentimos, lo que pensamos, lo que trabajamos, pero también es tan importante para expresar nuestras profundas diferencias entre Presidentes y Gobiernos, nuestras diferencias sobre políticas, programas, proyectos, principios y valores con algunos países del mundo (Morales, 2011).

De esta manera, en el período de sesiones de la Asamblea General, Morales ha puesto énfasis en temas como: el reclamo frente a Chile por una salida soberana al Pacífico; la crítica al sistema capitalista, vinculándolo con el rol de Estados Unidos en el mundo; la reivindicación de los derechos de las comunidades indígenas y la lucha contra la pobreza, la desigualdad y el cambio climático; el rechazo abierto a la mercantilización de los servicios básicos y la defensa de la hoja de coca en tanto elemento representativo de la cultura andina (Morales 2006; 2013).

Haciendo un recorrido de las medidas adoptadas por Naciones Unidas en el período 2006-2013 con respecto a las problemáticas que son de interés para el MAS, puede afirmarse que este ha "cosechado" algunos éxitos, ya sea acompañando proyectos de otras delegaciones o a través de su propio accionar. Entre estas se encuentran la Declaración de los Derechos de los Pueblos Indígenas (13 de septiembre de 2007), el reconocimiento del acceso al agua potable y al saneamiento como un derecho humano (28 de julio de 2010) y la despenalización del masticado - acullico- de la hoja de coca (11 de enero de 2013), contemplado en la Convención sobre Estupefacientes de 1961.

Teniendo en cuenta la pertenencia personal del presidente Morales y el contexto socio-demográfico de su país, la defensa de los derechos de las comunidades indígenas ha sido una de las cuestiones donde mayor hincapié ha hecho el mandatario. En su primera presentación ante la Asamblea General, Morales (2006) revalorizó la importancia 
de los movimientos indígenas en el mundo, destacando que la incorporación jurídica de sus derechos y demandas era un paso importante para reparar siglos de discriminación y exclusión. Por ello, la delegación boliviana acompañó con beneplácito el proyecto de resolución que presentó Perú para la adopción de la Declaración de los Derechos de los Pueblos Indígenas. Bolivia copatrocinó dicho documento, el cual fue aprobado por 143 votos a favor y cuatro votos en contra de Australia, Canadá, Nueva Zelanda y Estados Unidos (Naciones Unidas, 2007, pp. 20-21). La adopción de esta declaración constituye un gran avance en el reconocimiento universal de los derechos - tanto individuales como colectivos- de las comunidades originarias que habitan el planeta. El 7 de noviembre de 2007, Evo Morales elevó a rango de Ley de la República - No 3.760- los 46 artículos que conforman dicha declaración, estableciendo así un precedente en la región.

El proyecto sobre el acceso al agua potable y al saneamiento como derecho humano fue presentado por Bolivia a consideración del $108^{\circ}$ plenario de la Asamblea General. Estuvo copatrocinado por 33 Estados miembros de la organización, contó con 122 votos a favor, ninguno en contra y 41 abstenciones (Centro de Noticias ONU, 2010). La representación boliviana sostuvo que la iniciativa de su país fue motivada por la situación crítica de los recursos hídricos en el mundo y las problemáticas conexas - enfermedades, pobreza, conflictos, degradación ambiental, etc.- pero, fundamentalmente, por la necesidad de exhortar a los Estados a aceptar que este derecho es indispensable para garantizar el respeto de todos los derechos humanos (Naciones Unidas, 2010a, p. 6). En términos prácticos, y tal como lo establece la Resolución 64/292, dicha aceptación implica que los países y las organizaciones internacionales deben intensificar los esfuerzos materiales y tecnológicos para proporcionar a la población un acceso económico al agua y el saneamiento (Naciones Unidas, 2010b).

Cabe destacar que, desde 2006, el gobierno boliviano ha manifestado en la organización una firme oposición a la privatización de los servicios básicos, ya que esta constituye "la mejor forma de violar los derechos humanos" (Morales, 2006). La actual Constitución política del país andino, que entró en vigencia el 7 de febrero de 2009, contempla en su artículo 20 el acceso al agua y al alcantarillado como un derecho humano - universal y equitativo- que no puede ser objeto de concesión o privatización. Este reconocimiento constitucional como el impulso otorgado por la administración Morales a la temática a nivel internacional, se explica no solo por la cosmovisión que los pueblos indígenas poseen de los recursos naturales en general, sino también por la sensibilidad que reviste la problemática para la sociedad boliviana, tras el episodio de la Guerra del Agua en Cochabamba en el año 2000.

\section{Si Somos Americanos. Revista de Estudios Transfronterizos}


Por último, la defensa de la hoja de coca fue un asunto reivindicado en todas las presentaciones que Evo Morales realizó en la Asamblea General, haciendo un especial énfasis en su diferenciación con la cocaína. Morales ha defendido el consumo de la hoja de coca como parte de la idiosincrasia de las comunidades andinas y no como una práctica ilegal. Frente al hecho de que la hoja de coca se encuentra penalizada en la Convención de Estupefacientes de 1961, en junio de 2011 el gobierno boliviano anunció el retiro temporal de este acuerdo, por considerar que la prohibición del acullico constituye un error histórico (Los Tiempos, 2013b). A partir de entonces, Evo Morales lanzó una campaña internacional para sumar adhesiones a su propuesta de regresar a la Convención de Estupefacientes, con una reserva sobre el artículo que condena la utilización de la hoja de coca por contener alcaloides, que son empleados en la producción de cocaína. El secretario general de la ONU, Ban Ki-moon, presentó el caso a los países que son parte de la Convención, el 10 de enero de 2012, para que evaluaran la solicitud del Estado boliviano de permitir el mascado de la hoja de coca en su territorio (Centro de Noticias ONU, 2013) ${ }^{7}$. El despliegue diplomático de la administración boliviana logró incorporar esta reserva el 11 de enero de 2013, porque de los 62 países que podían bloquearla y, por ende, impedir la readmisión de Bolivia a la Convención, solo 15 se opusieron (Centro de Noticias ONU, 2013). A través de esta aprobación, Bolivia universalizó el reconocimiento de un recurso que está muy ligado a su historia como país y sociedad. El 10 de febrero de 2013, el Estado andino retornó oficialmente a la Convención de 1961, con la inclusión de la reserva correspondiente (Agencia Télam, 2013).

\section{Las relaciones Estado-Estado}

Analizando las relaciones bilaterales en el período 2006-2013, puede afirmarse que las mismas han atravesado un proceso de reconfiguración que se observa en: a) el fortalecimiento de ciertos vínculos regionales, aunque con características particulares Venezuela, Argentina y Brasil_; b) el ascenso de "nuevos socios" en la agenda de política exterior - China e Irán- y c) aquellas que denotan signos de conflictividad política, a saber, los casos de Estados Unidos y Chile.

La reserva planteada por Bolivia al artículo 49 de la Convención, señala: "El Estado Plurinacional de Bolivia se reserva el derecho de permitir en su territorio la masticación tradicional de la hoja de coca, el consumo y uso de la Hoja de Coca en su estado natural; para fines culturales y medicinales; como su uso en infusión, así como también el cultivo, el comercio y la posesión de la hoja de coca en la extensión necesaria para estos propósitos lícitos. Al mismo tiempo, el Estado Plurinacional de Bolivia seguirá tomando todas las medidas necesarias para controlar el cultivo de coca para prevenir su abuso y la producción ilícita de estupefacientes que pueden extraerse de las hojas. La adhesión efectiva de Bolivia a la citada Convención quedará sujeta a la autorización de dicha reserva" (Bolpress, 2013). 


\section{Venezuela}

Sin dejar de reconocer que la vinculación con Venezuela se entiende como uno de los contactos externos "tradicionales" de Bolivia, ya que ambos países han compartido el espacio de la Comunidad Andina de Naciones (CAN) hasta el retiro del Estado bolivariano en 2006, cabe destacar que a partir de la presidencia de Morales, la relación se ha intensificado de manera notoria. En este cambio de intensidad han incidido tanto la sintonía político-ideológica, como las posibilidades de cooperación económica que Venezuela le ofrece al país andino. Por su parte, Mesa Gisbert (2011) sostiene que el apoyo moral y material a la candidatura de Evo Morales en la campaña presidencial de 2005 marcó un punto de inflexión en el vínculo bilateral y en la política exterior en general. En palabras del ex presidente, Morales optó por un "seguidismo de la política exterior venezolana $[y]$ asumió en los tres primeros años de su gobierno una adscripción casi de reconocimiento del padrinazgo político de Chávez y por extensión —-más simbólico que efectivo- de Fidel Castro" (p. 12).

Morales ha visto con beneplácito - y también lo ha tomado como referencia- el carácter altermundista, contra-hegemónico y el fuerte discurso antiimperialista que ha marcado la política exterior llevada adelante por las administraciones Chávez (Lorenzini, 2012). Esta coincidencia de principios fue plasmándose en las críticas sobre las acciones militares de Estados Unidos - particularmente en Medio Oriente-; en el rechazo de los postulados neoliberales promovidos por los organismos financieros internacionales y en la adhesión de Bolivia a la Alianza Bolivariana para los Pueblos de Nuestra América (ALBA), el 29 de abril de 2006. Esta propuesta fue institucionalizada por Chávez y Castro el 14 de diciembre de 2004, con el fin de conformar un esquema de integración antagónico a las premisas neoliberales promovidas por el Acuerdo de Libre Comercio de las Américas (ALCA) (Canelas y Verdes, 2011, pp. 245-255).

Otro elemento que permite comprender el acercamiento entre ambos Estados, radica en el financiamiento de múltiples misiones sociales en Bolivia con fondos venezolanos. Dichas misiones tienen como objetivo atender problemáticas en materia de salud y educación de los sectores más pobres y excluidos. Entre estas, se encuentran: i) Batallón 51: atención médica gratuita; ii) Misión Moto Méndez: atención médica gratuita y ayuda técnica a personas con discapacidad; iii) Gran Mariscal José de Sucre: obras de infraestructura a comunidades desposeías; iv) Programa Yo, Sí Puedo: alfabetización; v) Operaciones cardiológicas a niños; vi) Becas Internacionales Gran Mariscal de Ayacu-

\section{Si Somos Americanos. Revista de Estudios Transfronterizos}


cho: programa de becas para jóvenes de escasos recursos para la formación universitaria (Información Embajada de Venezuela en Bolivia, 2013) ${ }^{8}$.

Una segunda instancia en la cual ha estado presente el gobierno venezolano radica en el financiamiento del programa "Bolivia cambia, Evo Cumple" entre 2006 y mediados de 2011. A través de este programa, Venezuela donó 460 millones de dólares para la realización de obras de infraestructura en barrios marginales y periféricos en territorio boliviano, tales como provisión de agua potable, centros asistenciales, construcción de espacios de recreación y acceso al saneamiento. Su puesta en marcha ha despertado fuertes críticas por parte de los partidos opositores, especialmente de Unidad Nacional (UN), quienes cuestionan la falta de transparencia en el manejo de los fondos y que los mismos no constituyen una donación, sino un crédito otorgado por el gobierno de Chávez (Notas de Prensa de la Cámara de Senadores de Bolivia, 2013).

Con respecto al aspecto económico-comercial del vínculo, a diferencia de los avances en el área social, la información proporcionada por el Instituto Boliviano de Comercio Exterior (IBCE) refleja que su evolución ha sido precaria, llegando incluso a ser negativa en el binomio 2011-2012 (IBCE, 2013a). En otras palabras, a pesar del fortalecimiento del vínculo y la concomitancia de ideas e intereses entre los primeros mandatarios, ambos Estados no han podido revertir el escaso dinamismo de la balanza comercial bilateral. Este dato no es menor ya que, en parte, permite reafirmar que la intensificación de la relación está asociada fundamentalmente a cuestiones político-ideológicas y a la capacidad de Venezuela de solventar proyectos de cooperación en el país andino. Esto abre signos de interrogación sobre "la fortaleza" que posee el vínculo, de seguir en la misma dirección más allá de los líderes políticos que lo impulsaron. A su vez, no debe dejarse de lado que el financiamiento venezolano de las misiones sociales fue viable en un contexto de precios internacionales altos en materia energética; situación que también pone en tela de juicio la continuidad de las mismas en caso de que los ingresos de Venezuela se encuentren en descenso ante una eventual caída del precio del crudo.

\footnotetext{
Según los datos proporcionados por la embajada de Venezuela en Bolivia, las misiones mencionadas han resultado en: Batallón 51 (150.000 consultas en el departamento de Beni); Misión Moto Méndez (84.000 evaluaciones); Gran Mariscal José de Sucre (459.520 personas beneficiadas); Programa Yo, Sí Puedo (150.000 personas alfabetizadas); 16 niños operados por patologías cardiológicas; Becas Gran Mariscal de Ayacucho (1.300 becas otorgadas) (2013). Con respecto a estas misiones, deben ser aclaradas dos cuestiones; por un lado, la dificultad de acceso a diversas fuentes de información — de organismos oficiales- que permitan corroborar estos datos, como los montos de dinero suministrados por el gobierno venezolano para cada una de ellas. Por otro lado, si bien Venezuela ha financiado estas misiones, Bolivia también cuenta con la asistencia de Cuba - recursos humanos- en el marco del ALBA.
} 


\section{Argentina y Brasil}

La asunción de Evo Morales fue coincidente con las administraciones de Néstor Kirchner (2003-2007) en Argentina e Inácio Lula da Silva en Brasil (2003-2010), quienes vieron con gran aprobación su victoria presidencial, por considerar que se encontraba dentro de la misma sintonía política. Uno de los ejes que favoreció el fortalecimiento de sendas vinculaciones, ha sido la compraventa de gas natural boliviano para abastecer la creciente demanda del hidrocarburo por parte de sus vecinos. En el caso argentino, cabe recordar que la crisis energética que eclosionó en el país en marzo de 2004 -y que derivó en la crisis del gas con Chile- obligó al gobierno de Kirchner a reiniciar las importaciones de gas natural para solventar su consumo doméstico (Ceppi, 2012; Lorenzini, 2011). Por su parte, en el caso de Brasil, las relaciones en torno a la energía se remontan a fines de la década del 90, cuando se habilitó el gasoducto binacional que alimenta de gas natural a la región industrial del país, particularmente, los Estados de Mato Grosso do Sul, São Paulo, Paraná, Santa Catarina y Rio Grande do Sul (Mathias y Cecchi, 2009) ${ }^{9}$.

Tanto las relaciones argentino-bolivianas como boliviano-brasileras transcurrieron sin mayores sobresaltos, hasta el anuncio de Evo Morales de nacionalización de los hidrocarburos el 1 de mayo de 2006. La medida tomó por sorpresa a los gobiernos de Kirchner y Lula, pero fue respetada por ser un acto inherente a la soberanía de un Estado (Clarín, 2006). En el plazo estipulado por el decreto de nacionalización -180 días- Argentina y Brasil renegociaron nuevos contratos de aprovisionamiento energético, aunque cada proceso tuvo características particulares. En los vínculos Argentina-Bolivia, el único tema que generó algunos entredichos fue el aumento de precio solicitado por el Ejecutivo boliviano por las exportaciones gasíferas (BBC, 2006). Finalmente, luego de varios encuentros ministeriales, este asunto fue resuelto en la reunión mantenida entre Kirchner y Morales el 29 de junio de 2006 - 5 dólares por millón de BTU frente a los 6 dólares requeridos por Bolivia-, la cual sentó las bases para el acuerdo entre las empresas Yacimientos Petrolíferos Fiscales Bolivianos (YPFB) y Energía Argentina Sociedad Anónima (ENARSA), suscripto el 19 de octubre del mismo año.

Por su parte, la renegociación contractual en la relación Bolivia-Brasil fue compleja, tensa y plagada de incertidumbre. La toma simbólica de las refinerías, que en ese entonces eran propiedad de PETROBRAS, por las Fuerzas Armadas bolivianas y la falta de un trato diferencial a dicha compañía que hasta 2006 había invertido 1,5 billones de

\footnotetext{
Entre ambos Estados también existe otra conexión, que es el gasoducto de Cuiabá, el cual abastece de gas natural a una usina termoeléctrica en el estado de Mato Grosso.
}

\section{Si Somos Americanos. Revista de Estudios Transfronterizos}


dólares y representaba alrededor del 18\% del Producto Interno Bruto (PIB) de Bolivia, ocasionaron momentos de tirantez (Cepik y Carra, 2006, p. 8). Tras numerosas reuniones entre los directivos de las empresas involucradas, los respectivos ministros de Energía y hasta los primeros mandatarios, el acuerdo entre YPFB y PETROBRAS se firmó en octubre de 2006, incorporando las disposiciones de la nacionalización. Unos meses más tarde, Lula y Morales acordaron la venta de las refinerías - Guillermo Elder Bell y Gualberto Villarroel-; la suba del precio del gas que abastece a la termoeléctrica de Cuiabá —de 1,19 a 4,20 dólares- y el pago a precios internacionales de las fracciones de los hidrocarburos líquidos - superiores a un valor calórico de 8.900 (kcal) por metro cúbico- contenidas en los volúmenes exportados de gas natural (Ministério das Relações Exteriores, 2007a, 2007b; Agência Petrobras, 2007).

En suma, si en las relaciones de Bolivia con Argentina y Brasil se tienen en cuenta factores como la mutua dependencia que al presente poseen en calidad de importador/ exportador; la importancia del gas natural para el sustento de la economía boliviana y que las exportaciones del hidrocarburo representan en los dos casos más del $90 \%$ de las exportaciones totales de Bolivia ${ }^{10}$, a diferencia de lo que acontece con Venezuela, el peso de la variable económico-comercial es muy significativo. Los entredichos surgidos pos nacionalización, evidenciaron esta cuestión, especialmente ante la necesidad de que los tres Estados poseen - por el momento-, de mantener en vigencia los contratos de compraventa de energía.

Además de la cuestión energética, la relación entre Bolivia y Brasil se vio afectada en 2013 por el caso Roger Pinto. El senador por Convergencia Nacional (CN), acusado de corrupción y malversación de fondos públicos, solicitó en mayo de 2012 asilo diplomático en la embajada de Brasil en La Paz, argumentando que era un perseguido político de la administración Morales. El 8 de junio del mismo año, Brasil aceptó el pedido de asilo, lo cual fue cuestionado por el gobierno boliviano, quien negó su condición de perseguido y la posibilidad de otorgarle el salvoconducto (La Razón, 2013a). Tras permanecer 455 días asilado, Pinto huyó hacia Brasil en un auto de la embajada y con ayuda del encargado de Negocios, Eduardo Saboia, quien afirmó que esta acción fue un cuestión humanitaria ante la supuesta depresión del senador boliviano (Infobae, 2013). Rápidamente, Morales presentó una nota de protesta diplomática y frente a los hechos, Dilma Rousseff decidió remover de sus cargos a los funcionarios de la embajada de Brasil y a su canciller, Antonio Patriota (Los Tiempos, 2013a). Con ello, Evo Morales dio por resuelta la problemática en

10 En las relaciones Argentina-Bolivia, las exportaciones de gas natural representan el $91 \%$ de las exportaciones de Bolivia hacia este país. En el caso de Bolivia-Brasil, las ventas del hidrocarburo constituyen el $97 \%$ de las exportaciones bolivianas hacia el mercado vecino (IBCE, 2013b; IBCE, 2013e). 
el encuentro que mantuvo con Rousseff en el marco de la Cumbre de la Unión de Naciones Suramericanas (UNASUR), realizada en agosto de 2013 en Surinam.

\section{China e Irán}

El ascenso de China e Irán en los lineamientos de política exterior boliviana en tiempos de Evo, se explica, en términos generales, en la voluntad del gobierno boliviano de diversificar el abanico de relaciones bilaterales, de acuerdo a las oportunidades que ofrece el entorno internacional. Sin embargo, si se comparan el caso chino y el iraní, puede afirmarse que se diferencian en cuanto a la "esencia" de las respectivas agendas bilaterales.

No es ninguna novedad que China, por su ritmo de crecimiento económico y demográfico, es uno de los principales consumidores de alimentos y recursos energéticos en el mundo. El intercambio comercial entre China y Bolivia evidencia que en sus economías existe una clara complementariedad, debido a que mientras el país andino le exporta grandes volúmenes de minerales — plata, estaño, zinc, antimonio, etc. —; el gigante asiático le vende más de 4.000 productos manufacturados (IBCE, 2013c) ${ }^{11}$. Como es de esperar, y según los datos del IBCE, la balanza comercial es absolutamente deficitaria para Bolivia; tendencia que se ha mantenido entre 2007 y 2012. A modo de ejemplo, frente a los 1.171 millones de dólares en concepto de ventas realizadas por Bolivia en dicho período, las importaciones alcanzaron los 3.843 millones de dólares, ocupando en 2012 el tercer lugar entre los proveedores del país (IBCE, 2013c).

En aras de fortalecer el vínculo bilateral, en septiembre de 2011, Bolivia y China firmaron seis acuerdos de cooperación para el emprendimiento de proyectos conjuntos en materia de agricultura, minería, comunicaciones, energía, incentivos a las inversiones y seguridad alimentaria (Bolpress, 2011). Dentro de estos, sobresalen el crédito chino -300 millones de dólares - otorgado para la construcción del primer satélite boliviano, denominado Túpac Katari, el cual contribuirá a que el país andino reduzca la utilización de satélites extranjeros y la posibilidad de asociación para la industrialización de las reservas de litio en Bolivia, consideradas una de las mayores del mundo (Bolpress, 2011; Los Tiempos, 2011). Como afirma Zuleta Calderón (2011), los chinos pueden ser socios importantes en las primeras fases de aprovechamiento y desarrollo del litio y otros recursos evaporíticos, pero el gobierno tiene el gran desafío de evitar errores de cálculos, ya

11 Entre los productos más destacados dentro de las importaciones, se encuentran las motocicletas, las máquinas automáticas y los tubos para oleoductos.

\section{Si Somos Americanos. Revista de Estudios Transfronterizos}


que podrían originarse consecuencias catastróficas para la economía nacional. Esto indica que al momento de llevar adelante un proyecto de esta naturaleza, el Estado andino debería tener una presencia activa en las etapas de exploración y extracción, pero sobre todo en lo que respecta a su industrialización.

Por su parte, el vínculo político puede caracterizarse como cordial y amistoso desde el restablecimiento de relaciones diplomáticas a mediados de la década del 80 (Barrios, 1997, p. 3). Tradicionalmente, Bolivia ha mantenido la política de "una sola China"; cuestión que fue ratificada en uno de los primeros encuentros entre el ministro de Relaciones Exteriores boliviano, David Choquehuanca, y su homólogo chino, Yang Jiechi, en diciembre de 2007 (Oficina del Consejo Económico-Comercial de la Embajada de China en Bolivia, 2007).

La vinculación entre Bolivia e Irán se inserta en un contexto completamente diferente a los contactos sino-bolivianos. Fernández (2009) define este acercamiento como una "anomalía", ya que carece de antecedentes históricos, culturales o políticos - las relaciones diplomáticas datan de 2007-y tampoco posee relevancia económico-comercial (p. 2). Las exportaciones de Irán a Bolivia representan un 0,0021\% del total que este país le vende al mundo, y en el caso de las exportaciones bolivianas hacia Irán, estas poseen un comportamiento similar, a saber, el 0,0022\% de las ventas totales del Estado andino, según datos entregados por el Instituto Boliviano de Comercio Exterior (El Día, 2012). Ante esto, ¿qué factores han favorecido el incremento de los contactos bilaterales? En primer lugar, debe considerarse que la intensificación del vínculo boliviano-iraní replica, en gran medida, lo ocurrido en las relaciones Irán-Venezuela. La retórica antiestadounidense de las administraciones de Chávez y Ahmadinejad, y las posibilidades de negocios conjuntos en materia petrolera no solo potenciaron la relación entre ambos países, sino que, además, Chávez ha sido el nexo para que esta dinámica se repita en la región, en particular, en el esquema del ALBA (Paredes, 2010, pp. 197-198). En segundo lugar, los gobiernos de Bolivia e Irán se han brindado apoyo en las demandas presentadas ante los organismos internacionales. Irán ha respaldado la defensa de la hoja de coca "como un derecho inalienable del pueblo boliviano" y como contrapartida, Bolivia defiende el programa nuclear iraní para fines pacíficos.

\section{Estados Unidos}

Desde el ascenso del MAS, las relaciones entre Bolivia y Estados Unidos han dado un giro importante. La retórica antiimperialista y contrahegemónica y la intensificación 
de los contactos con Venezuela e Irán fueron causando cierto recelo en la administración de George W. Bush, de modo tal que el vínculo boliviano-estadounidense fue tornándose hostil y conflictivo. Este estado de "baja intensidad" marca un punto de inflexión en comparación con el pasado, puesto que, como se mencionó en líneas anteriores, la relación se caracterizaba por encontrarse en plena sintonía. Durante el 2008 - año convulsionado para la administración Morales- sucedieron dos hechos que favorecieron que la crisis bilateral fuera in crescendo: la declaración de persona non grata del entonces embajador de Estados Unidos en La Paz, Philip Goldberg, el 10 de septiembre; y la suspensión por tiempo indefinido de las actividades de la DEA en el mes de noviembre (Bolpress, 2008; El Mundo, 2008; Clarín, 2008; Los Tiempos, 2008). Cabe recordar que todo el 2008 fue un año crítico para la sociedad boliviana, donde los enfrentamientos entre el oficialismo y la oposición pusieron en juego la fortaleza institucional del país. Las pujas por la aprobación del texto constitucional y las demandas de autonomía departamental de la denominada medialuna - Santa Cruz, Tarija, Pando y Beni-ocasionaron múltiples momentos de tensión y violencia que, de cierta manera, sembraron dudas sobre la capacidad del gobierno de Morales para continuar con su gestión. En este contexto fue que el Ejecutivo tomó las decisiones señaladas supra, bajo el argumento de que Estados Unidos, a través de su embajador y de su agencia antidrogas, buscaban desestabilizarlo. Morales señaló que los contactos de estas figuras con sectores opositores y sus actividades de espionaje eran indicios de que Estados Unidos conspiraba no solo contra su gobierno, sino también contra la democracia (El Mundo, 2008; Los Tiempos, 2008).

El Departamento de Estado hizo público su rechazo a las acusaciones del gobierno boliviano y lamentó el impasse del accionar de la DEA tras más de tres décadas de trabajo en el país. Frente a esta situación, la administración de Bush hijo descertificó a Bolivia como país de tránsito y productor de drogas y decidió interrumpir los beneficios comerciales de la Ley de Promoción Comercial Andina y Erradicación de la Droga (ATPDEA, en inglés), argumentando que el país andino no había avanzado lo suficiente en su lucha contra el narcotráfico (Embajada de Bolivia en Washington, 2013) ${ }^{12}$.

Ante la crisis en el vínculo bilateral, a partir de mayo de 2009, funcionarios de ambos países llevaron adelante una serie de reuniones, con el objetivo de solucionar los problemas existentes y dar inicio a un nuevo período en la relación (Embajada de Bolivia en Washington, 2013). Luego de varios encuentros e intercambios de opiniones, los go-

12 La ATPDEA es una continuidad de la ATPA, la cual entró en vigencia en agosto de 2002. A pesar de que la administración Morales ha intentado restarle importancia a su suspensión, la ATPDEA ha tenido un gran impacto en Bolivia, porque ha favorecido las exportaciones de productos no tradicionales, tales como calzado, madera y joyas. 
biernos de Bolivia y Estados Unidos suscribieron el 7 de noviembre de 2011 un Convenio Marco de Mutuo Respeto y Colaboración. Entre sus metas principales, se encuentran la promoción del comercio conjunto y la responsabilidad compartida en la lucha contra el tráfico de drogas - sin incluir el tema de ATPDEA - bajo el respeto de la igualdad soberana de los Estados y el respeto de la no injerencia en los asuntos internos (Convenio Marco de Mutuo Respeto y Colaboración, 7 de noviembre de 2011). A pesar de los intentos por recomponer el vínculo, este ingresó nuevamente a una etapa de tensión ante la negativa de extradición de Gonzalo Sánchez de Lozada por parte del gobierno de Obama en septiembre de $2012^{13}$; la expulsión de la USAID del territorio boliviano en mayo de $2013^{14} \mathrm{y}$ el caso Edward Snowden en julio del mismo año. Con respecto a este último, es importante recordar que Evo Morales se encontraba regresando a su país tras una reunión de los países exportadores de gas en Moscú, cuando cuatro países europeos -Francia, España, Italia y Portugal- decidieron negarle, por "cuestiones técnicas", la autorización al vuelo presidencial para atravesar sus respectivos espacios aéreos. No obstante, desde la Cancillería boliviana se informó que, en realidad, el desvío del avión de Morales se basaba en la sospecha de que el mismo llevaba al ex técnico de la CIA, quien se encontraba en territorio ruso ${ }^{15}$ por revelar que Estados Unidos realiza espionaje internacional a través de sus agencias.

A pesar de que en este incidente estuvieron directamente involucrados los cuatro Estados europeos ya señalados, la administración Morales también responsabilizó a Estados Unidos en este hecho, afirmando que "ha pensado que Snowden está en el avión presidencial y que los países europeos han actuado de manera consensuada" (El Mundo, 2013). Tras los respectivos pedidos de disculpas, Morales dio por superado el problema en su visita al Viejo Continente en septiembre de 2013, aunque no ha ocurrido lo mismo con Estados Unidos, quien ha negado en reiteradas oportunidades su responsabilidad en el desarrollo de los acontecimientos (Última Hora, 2013).

En definitiva, en el período 2006-2013, las relaciones Bolivia-Estados Unidos se han caracterizado no solo por su baja intensidad, sino también por la tensión constante. Los acontecimientos enumerados dan cuenta que los vínculos se han dirimido según un esquema de acción y reacción, es decir, que un hecho de una de las partes es contestado

13 Desde su renuncia al poder presidencial, el 17 de octubre de 2003, por los acontecimientos de la Guerra del Gas, Sánchez de Lozada se encuentra residiendo en Estados Unidos. Con su pedido de extradición -elevado al Departamento de Estado en abril de 2009- el gobierno Bolivia pretende enjuiciarlo en calidad de responsable de las muertes del llamado "Octubre Negro" (El Deber, 2012).

14 Según lo afirmado por Evo Morales, la expulsión de la USAID se justifica en que dicha agencia ejecutaba sus proyectos solo con fines políticos, impulsando así la división de las organizaciones sociales (Paredes, 2013).

15 Finalmente, el gobierno ruso le concedió asilo temporal a Snowden en agosto de 2013 (Duch, 2013). 
de manera inmediata por la otra. Si bien, el estadio en el cual se encuentra la vinculación bilateral a nivel político se corresponde con el discurso antiimperialista de Morales, en el ámbito económico-comercial no ocurre lo mismo, puesto que Estados Unidos continúa siendo el tercer destino de las exportaciones totales de Bolivia, después de Brasil y Argentina (IBCE, 2013b).

\section{Chile $^{16}$}

Las relaciones chileno-bolivianas constituyen un caso especial, puesto que el peso de un pasado conflictivo ha marcado el destino de las mismas. En palabras de Jeffs (2012), "la guerra fuera de las consecuencias territoriales, dejó una secuela de muerte y heridos, como también un clima de odiosidad, desvalorización y revanchismo que desde allí ha ensombrecido la relación entre nuestros pueblos" (p. 4). Luego de varios intentos de negociaciones que terminaron por fracasar y sin mantener relaciones diplomáticas desde 1978, el buen clima inicial entre los gobiernos de Evo Morales y Michelle Bachelet generó la esperanza - particularmente en la administración boliviana - de poder acercar a los dos países. Los primeros signos en esta dirección fueron la presencia de Morales en la asunción de Bachelet en marzo de 2006 y la decisión de trabajar en una agenda compartida sin restricciones - conocida como la Agenda de los Trece Puntos- donde se incluyó la cuestión de la mediterraneidad boliviana (Lorenzini, 2011).

La incorporación de este tema en el tratamiento bilateral fue subrayada por el presidente boliviano en su discurso ante la Asamblea General de Naciones Unidas, el 26 de septiembre de 2007:

Y aquí, también quiero expresarles, ustedes saben que tenemos un problema histórico con la hermana República de Chile, el tema del mar, quiero decirles que hasta ahora hemos sentado cierta confianza, confianza de pueblo a pueblo, confianza de gobierno a gobierno, confianza de Presidenta a Presidente, bajo la Diplomacia de los Pueblos y queremos apostar a resolver las reivindicaciones históricas pero en el marco de la complementariedad, porque los países vecinos, países de Latino América necesitamos complementarnos (Morales, 2007, p. 29).

16 Teniendo en cuenta que el tema marítimo en las vinculaciones entre Chile y Bolivia constituye una materia sensible, compleja y de muy larga data, y que a raíz del mismo han oscilado entre el "conflicto" y la cooperación, en este apartado solo se abordan los hechos más significativos desde la llegada de Evo Morales. Analizar más pormenorizadamente esta cuestión, excede ampliamente los fines del presente trabajo.

\section{Si Somos Americanos. Revista de Estudios Transfronterizos}


A lo largo de la administración Bachelet, el calendario de reuniones del Grupo de Trabajo sobre Asuntos Bilaterales y del Mecanismo de Consultas Políticas BoliviaChile fue cumplido tal cual lo pactado, pero no se presentaron avances con respecto a la cuestión marítima, a diferencia de otras áreas como defensa e integración (Rosales, 2011). No obstante, en líneas generales, los contactos entre los gobiernos de Morales y Bachelet pueden ser evaluados como positivos, donde ambos dieron señales de la existencia de voluntad política para mejorar la calidad de la relación. El cumplimiento de los encuentros en tiempo y forma posibilitó la profundización del diálogo, y le ha aportado un "alto nivel de continuidad al vínculo bilateral" con respecto a los gobiernos anteriores (Rosales, 2011, p. 79).

El cambio de signo político en el Ejecutivo chileno tras la asunción de Sebastián Piñera, en marzo de 2010, no generó, en un primer momento, inquietudes en la administración Morales. Es más, ambos mandatarios ratificaron en una reunión, mantenida en diciembre del mismo año, su compromiso para continuar trabajando en la agenda conjunta establecida durante el mandato de Bachelet y afirmaron la necesidad de conformar una comisión permanente para el seguimiento de la misma (Bolpress, 2010).

El 7 de febrero de 2011, se realizó en La Paz la primera reunión de vicecancilleres en 60 años para analizar la cuestión marítima, aunque esta finalizó sin resultados (La Razón, 2013b). Frente a estos acontecimientos, en el mes de marzo, Morales le reclamó a Piñera una salida libre y soberana al Pacífico, planteando la posibilidad de llevar su demanda a tribunales internacionales; cuestión que finalmente se concretó en abril de 2013. El mandatario chileno afirmó que el anuncio de su homólogo boliviano se constituye en una "pretensión inaceptable" y "se aparta de los términos acordados por ambos gobiernos" (Durán y Artaza, 2011). A partir de la decisión de Bolivia de llevar esta cuestión a la Corte Internacional de Justicia, las dos administraciones fueron endureciendo cada vez más sus respectivas posiciones, dando cuenta de la existencia de dos miradas completamente diferentes sobre la problemática. Esto se manifiesta con claridad en los discursos brindados por los mandatarios en diferentes instancias multilaterales. Para Morales, acudir a un tribunal internacional radica en que el enclaustramiento del país es "producto de una guerra injusta, una invasión” [...] “¿Quiénes invadieron? Oligarquías chilenas de aquellos tiempos con las empresas inglesas" $(2011 ; 2013)$. En tanto, para Piñera, "entre Chile y Bolivia no existen asuntos territoriales pendientes. Ellos quedaron resueltos por el Tratado de Paz y Amistad de 1904 [... y y como la propia Bolivia lo ha reconocido, el Tratado fue fruto de una negociación libre y consentida" (2011). Estos lineamientos fueron reiterados por el ministro de Relaciones Exteriores, Alfredo Moreno, ante la Asamblea General en septiembre de 2012, quien sostuvo que "Bolivia carece de un derecho para 
reclamar una salida soberana al mar" [...] Chile no ha dejado de expresar a Bolivia su disposición al diálogo fraterno en las manos de Bolivia está aceptar la invitación” (2012).

Otro hecho que contribuyó a la tirantez del vínculo, fue la detención de tres soldados bolivianos por la fuerza policial chilena el 25 de enero de 2013, acusados de ingresar de manera ilegal al territorio con portación de armas. Desde la óptica del gobierno boliviano, esta detención constituyó "un gesto inamistoso" y "un acto de mala vecindad", porque los detenidos se encontraban en una operación para capturar contrabandistas (La Tercera, 2013). Este episodio confuso terminó por resolverse sin mayores inconvenientes, debido a que el 1 de marzo de 2013 la justicia chilena dejó en libertad a los tres soldados, luego de acordar la suspensión del proceso penal en Chile, a cambio de abandonar el país en un plazo de 24 horas.

El abordaje de los principales acontecimientos de la agenda boliviano-chilena, durante la administración Morales, da cuenta de dos momentos; el primero, coincidente con la gestión de Bachelet, donde la relación logró ser encauzada en términos de diálogo político; el segundo, a partir de Piñera, caracterizado por una gran distancia, en el cual ninguno de los dos gobiernos demostró voluntad en continuar trabajando sobre las pautas establecidas con anterioridad. El panorama inmediato es la incertidumbre, ya que habrá que esperar no solo los resultados de las elecciones presidenciales en Chile en 2013 y en Bolivia en 2014, sino también el pronunciamiento de la Corte Internacional de Justicia sobre la cuestión marítima ${ }^{17}$.

\section{Conclusiones}

El recorrido realizado por los hechos y las vinculaciones más relevantes de la política exterior boliviana desde la llegada de Evo Morales, permiten reafirmar la idea de que la misma ha experimentado notables transformaciones, si se la compara con la proyección externa sostenida por los gobiernos anteriores. Así, en su objetivo de establecer un punto de inflexión con el pasado, la administración Morales emprendió —utilizando los lineamientos expuestos por Lasagna - un proceso de cambio, donde se observa una suerte de convivencia entre la reestructuración y el ajuste. Los factores que indican que la política exterior se encuentra reestructurándose, son los principios retóricos que la sustentan -indigenismo; antiimperialismo y ambientalismo-; una fuerte impronta político-ideológica versus la preponderancia de lo económico-comercial de los 90; un mayor

${ }_{17}$ Al momento de realizar este artículo no se habían efectuado los comicios electorales en Chile.

\section{Si Somos Americanos. Revista de Estudios Transfronterizos}


grado de diversificación de las relaciones establecidas y un perfil más visible y dinámico en el ámbito de Naciones Unidas. Por su parte, el ajuste se manifiesta con pequeñas alteraciones, pero sin representar un cambio estructural, siendo los ejemplos más significativos los vaivenes entre el diálogo y la discordia por una demanda siempre presente en la agenda boliviana, como es la salida soberana al Pacífico y el fortalecimiento del rol del Estado - a través de la figura de YPFB - en el comercio energético con Argentina y Brasil.

Retomando el análisis del plano multilateral de la política exterior de Bolivia, el gobierno de Morales ha apoyado e impulsado en el ámbito de Naciones Unidas —mediante una diplomacia activa - el debate de temáticas que son parte de la política doméstica del país. En este sentido, la defensa de los derechos colectivos de los pueblos indígenas; la lucha contra la privatización de los servicios básicos y el reclamo por la despenalización de la hoja de coca merecen una doble lectura: por un lado, su universalización es un mérito de la administración actual, quien ha sentado precedentes sobre el tratamiento de asuntos que durante años habían sido relegados. Por el otro, dicho impulso también puede asociarse a que estos temas revisten un gran interés en la agenda política del MAS.

El plano bilateral da cuenta de cómo las relaciones de Estado-Estado han sido rediseñadas a partir de 2006. Sin lugar a dudas, los vínculos más innovadores se encuentran en el ascenso de China e Irán como socios, comercial en el primer caso y político-ideológico en el segundo. Por su parte, el eje compuesto por Venezuela, Argentina y Brasil también presenta diferencias en su interior, puesto que mientras los contactos con el país caribeño se asocian principalmente a la mancomunidad de ideas de sus gobiernos $-\mathrm{y}$ en menor medida la cooperación económica - las relaciones de Bolivia con Argentina y Brasil se cimentan básicamente en la compraventa de gas natural. Por último, los casos de Estados Unidos y Chile poseen en común el hecho de ser los más conflictivos del período. No obstante, el caso chileno-boliviano reviste una mayor complejidad, debido a la impronta de un pasado, que para Bolivia aún no ha podido ser superado.

\section{Referencias}

Agência Petrobras. (26 de junio de 2007). Aclara Petrobras en la conferencia de prensa la transferencia de las refinerías para YPFB.

Agencia Télam. (10 de febrero de 2013). Bolivia regresó a la Convención sobre drogas luego de que la ONU aceptara el masticado de coca. 
Barrios, R. (julio de 1997). Las relaciones de Bolivia con los países de Asia-Pacífico. En Reunión de América Latina y el Caribe del Centro de Estudios sobre Asia-Pacífico. Organizada por el SELA con el auspicio del INTAL-BID. Recuperado de http://www.iadb.org/ intal/intalcdi/PE/2012/10480a11.pdf

BBC. (13 de junio de 2006). Bolivia-Argentina: sin acuerdo por gas.

Boletín Electrónico Bisemanal IBCE. (28 de marzo de 2013a). Relación Comercial BoliviaVenezuela, № 205.

Boletín Electrónico Bisemanal IBCE. (24 de enero de 2013b). Comercio Exterior de Bolivia 2012. No 188.

Boletín Electrónico Bisemanal IBCE. (14 de febrero de 2013c). Relación Comercial BoliviaChina. № 193.

Boletín Electrónico Bisemanal IBCE. (24 de junio de 2013d). Relación Comercial BoliviaBrasil. No 229.

Boletín Electrónico Bisemanal IBCE. (22 de agosto de 2013e). Relación Comercial BoliviaArgentina. № 246.

Bolpress. (10 de septiembre de 2008). Evo declara persona no grata al Embajador de EE.UU. y le pide que se vaya del país.

Bolpress. (17 de diciembre de 2010). Bolivia y Chile ratifican agenda de 13 puntos y conforman comisión permanente.

Bolpress. (23 de septiembre de 2011). Bolivia y China firman seis acuerdos de cooperación.

Bolpress. (11 de enero de 2013). Bolivia vuelve a la Convención de Estupefacientes de la ONU.

Canelas, M., y Verdes, F. (2011). La nueva política exterior boliviana (2005-2010): más autonomía y nuevos desafíos. En Í. Errejón y A. Serrano (eds.), ¡Ahora es cuándo, carajo!, del asalto a la transformación del Estado en Bolivia (pp. 239-266). Barcelona, España: El Viejo Topo.

146 Si Somos Americanos. Revista de Estudios Transfronterizos 
Centro de Noticias ONU. (28 de julio de 2010). Asamblea General reconoce como derecho humano el acceso al agua. Recuperado de http://www.un.org/spanish/News/story. asp?NewsID=18853\#.UpUpb9LuJPI

Centro de Noticias ONU. (11 de enero de 2013). Bolivia reaccederá a Convención Estupefacientes con excepción de masticado de hoja de coca. Recuperado de http://www.un.org/ spanish/News/story.asp?NewsID=25415\#.UpUs_dLuJPI

Cepik, M., y Carra, M. (2006). Nacionalização boliviana e desafios da América do Sul, Análise de Conjuntura 4. Recuperado de http://www.plataformademocratica.org/Publicacoes/22205.pdf

Ceppi, N. (septiembre 2012). La cuestión energética en la agenda sudamericana. Un recorrido de las relaciones Argentina-Bolivia y Bolivia-Brasil en la primera década del siglo XXI. En X Congreso Nacional y III Congreso Internacional de Ciencia Politica y Relaciones Internacional, Facultad de Ciencia Política de Relaciones Internacionales, Universidad Nacional de Rosario. Rosario de Santa Fe, Argentina.

Clarín. (2 de mayo de 2006). Cumbre entre Kirchner, Lula y Evo Morales por la nacionalización de los hidrocarburos en Bolivia.

Clarín. (1 de noviembre 2008). Evo suspendió las operaciones de la DEA en Bolivia y acusó a sus agentes de espionaje.

Durán, P., y Artaza, F. (24 de marzo de 2011). Morales pone en jaque relación con Chile al amenazar con demanda. La Tercera.

Duch, J. P. (2 de agosto de 2013). Cobija Rusia a Snowden. La Jornada.

El Deber. (7 de septiembre de 2012). Estados Unidos niega extradición de Sánchez de Lozada.

El Día. (19 de junio de 2012). Bolivia e Irán tienen una relación comercial casi nula.

El Mundo. (11 de septiembre de 2008). Evo declara persona non grata al Embajador de EE.UU. por dividir a Bolivia.

El Mundo. (4 de julio de 2013). Bolivia devuelve la petición de extradición de Snowden a EE.UU. al no estar en el país. 
Embajada de Bolivia en Estados Unidos. (20 de noviembre de 2013). Relaciones bilateralesSituación Actual. Recuperado de http://www.bolivia-usa.org/index.php?option=com_ content\&view $=$ article\&id $=80 \&$ Itemid $=80$ \&lang $=$ es

Embajada de Bolivia en Estados Unidos. (7 de noviembre de 2011). Convenio Marco de Relaciones Bilaterales de Mutuo Respeto y Colaboración entre el gobierno del Estado Plurinacional de Bolivia y el gobierno de los Estados Unidos de América Washington. Recuperado de http://www.bolivia-usa.org/pdf/convenio-marco-espanol.pdf

Embajada de Venezuela en Bolivia. (5 de noviembre de 2013). Relaciones BilateralesCooperación Internacional. Recuperado de http://bolivia.embajada.gob.ve/index. php?option=com_content\&view=article\&id=7\&Itemid=10\&lang $=$ es

Fernández, G. (marzo 2009). La política exterior boliviana. En Primer Encuentro Internacional del Observatorio Andino de Política Exterior OBANPEX. Quito, Ecuador. Recuperado de http://www.flacsoandes.org/internacional/?page_id=442

Infobae. (27 de agosto de 2013). Ayudó a Roger Pinto a escapar porque oyó la voz de Dios.

Jeffs, L. (noviembre 2012). Las relaciones chileno-bolivianas: aproximación histórica y desafíos. En VI Congreso de Relaciones Internacionales. Instituto de Relaciones Internacionales. Universidad Nacional de La Plata. La Plata, Argentina. Recuperado de http:// www.iri.edu.ar/VI_congreso/ponencias/CASTRO,\%20Leonardo\%20Jeffs_Las\%20relaciones\%20chileno-bolivianas.pdf

Kafka, J. (1995). Toma de decisiones y Política Exterior Boliviana. En R. Barrios, Política Exterior Boliviana (pp. 31-64). La Paz, Bolivia: UDAPEX, ILDIS.

La Razón. (28 de mayo de 2013a). Cancillería ratifica que no dará el salvoconducto a Pinto.

La Razón. (23 de abril de 2013b). Cronología del conflicto por demanda boliviana a Chile de una salida al mar.

La Tercera. (18 de febrero de 2013). Bolivia denuncia a Chile ante las Naciones Unidas por detención de tres soldados en Colchane.

Lasagna, M. (1995). Las determinantes internas de la política exterior: un tema descuidado en la teoría de la política exterior. Estudios Internacionales 28 (111), 387-409.

148 Si Somos Americanos. Revista de Estudios Transfronterizos 
Lorenzini, M. E. (2011). Política exterior, alianzas estratégicas y energía en América Latina. Las relaciones argentino-chilenas bajo la lupa. Rosario, Argentina: Editorial Homo Sapiens.

Lorenzini, M. E. (septiembre 2012). Las estrategias de inserción internacional de Argentina, Chile y Venezuela: primera aproximación a un análisis comparado. En $X$ Congreso Nacional y III Congreso Internacional de Ciencia Política y Relaciones Internacional, Facultad de Ciencia Política de Relaciones Internacionales, Universidad Nacional de Rosario. Rosario de Santa Fe, Argentina.

Los Tiempos. (11 de agosto de 2011). Bolivia sella acuerdos con China para satélite y desarrollo de litio.

Los Tiempos. (2 de noviembre de 2008). Evo suspende operaciones de la DEA en Bolivia.

Los Tiempos. (30 agosto de 2013a). Brasil retira a sus diplomáticos de la Embajada en La Paz.

Los Tiempos. (10 de enero de 2013b). Trece países objetan hasta ahora la petición de Bolivia ante la ONU.

Machado, F. (2011). Partido y algo MAS. Descripción y análisis del Movimiento al Socialismo (MAS) como fenómeno político en Bolivia. Decursos 23 (XIII), 173-212.

Mathias, M., y Cecchi, J. (noviembre 2009). Industria de gas natural en Brasil: pasado, presente y futuro. En IV Congreso Iberoamericano de Regulación Económica, San José. Recuperado de http://www.cne.es/cgi-bin/BRSCGI.exe?CMD=VEROBJ\&MLK $\mathrm{OB}=565699540303$

Mayorga, F. (2008). El gobierno de Evo Morales: cambio político y transición estatal en Bolivia En Y. Murakami (ed.), Tendencias politicas actuales en los países andinos. CIAS Discussion Paper 5 (pp. 21-40). Kyoto, Japón: Kyoto University.

Mayorga, F., y Rodríguez, B. (2010). Nacionalismo e indigenismo en el gobierno del MAS. Temas y Debates 20 (14), 97-122.

Mesa, C. (2011). Bolivia y Brasil: los meandros del camino. Working Paper 13. Recuperado de http://www.fes-seguridadregional.org/index.php?option=com_booklibrary\&task=vie w\&id $=4263 \&$ catid $=253 \&$ Itemid $=319$ 
Ministério das Relações Exteriores. Atos Internacionais. (2007a). Acta de Brasilia, Brasil, 14 de febrero. Recuperado de http://www.itamaraty.gov.br/

Ministério das Relações Exteriores. Atos Internacionais. (2007b). Ata de Reunião Ministerial sobre o preço do gás para a termelétrica de. Atos Internacionais, 14 de febrero. Recuperado de http://www.itamaraty.gov.br/

Morales, E. (2006). Discurso del Presidente de Bolivia en la Asamblea General de Naciones Unidas. Recuperado de http://daccess-dds-ny.un.org/doc/UNDOC/GEN/ N06/527/40/PDF/N0652740.pdf?OpenElement

Morales, E. (2007). Discurso del Presidente de Bolivia en la Asamblea General de Naciones Unidas. Recuperado de http://daccess-dds-ny.un.org/doc/UNDOC/GEN/ N07/517/14/PDF/N0751714.pdf?OpenElement

Morales, E. (2011). Discurso del Presidente de Bolivia en la Asamblea General de Naciones Unidas. Recuperado de http://www.rree.gob.bo/webmre/principal.aspx?pagina=np13. htm\&ruta=notasprensa/2011/2011_septiembre/

Morales, E. 2013. Discurso del Presidente de Bolivia en la Asamblea General de Naciones Unidas. Recuperado de http://daccess-dds-ny.un.org/doc/UNDOC/GEN/N13/485/72/ PDF/N1348572.pdf?OpenElement

Moreno, A. (28 de septiembre 2012). Debate General en la Asamblea de Naciones Unidas. Ministerio de Relaciones Exteriores de Chile. Recuperado de http://gadebate.un.org/ sites/default/files/gastatements/67/CL_es.pdf

Naciones Unidas. (13 de septiembre de 2007). Declaración de las Naciones Unidas sobre los derechos de los pueblos indígenas. A/61/PV.107. Nueva York, Estados Unidos: Asamblea General de las Naciones Unidas.

Naciones Unidas. (28 de julio de 2010). The human right to water and sanitation (A/64/ PV.108). Nueva York, Estados Unidos: Asamblea General de las Naciones Unidas.

Notas de Prensa de la Cámara de Senadores de Bolivia. (29 de mayo de 2013). Vicepresidente desvela 7 mentiras de Doria Medina sobre Bolivia Cambia, Evo Cumple.

Oficina del Consejo Económico-Comercial de la Embajada de China en Bolivia. (21 de diciembre de 2007). China y Bolivia se comprometen a impulsar las relaciones bilaterales. Recuperado de http://bo2.mofcom.gov.cn/article/bilateralvisits/200712/20071205297691.shtml

150 Si Somos Americanos. Revista de Estudios Transfronterizos 
Paredes, I. (2 de mayo de 2013). Evo expulsa a USAID de Bolivia tras acusarla de injerencia política. La Razón.

Paredes, R. (2010). Argentina: la gran equilibrista en los temas vinculados a Medio Oriente: una región lejana y sensible en la política exterior. En La política exterior de Cristina Fernández. Apreciaciones promediando su mandato, Tomo V (pp. 183-215). Rosario, Argentina: Editorial UNR.

Piñera, S. (2011). Discurso del Presidente de Chile en la Asamblea General de Naciones Unidas. Recuperado de http://gadebate.un.org/sites/default/files/gastatements/66/ CL_es.pdf

Plan Nacional de Desarrollo. (2006). Ministerio de Planificación del Desarrollo, Estado Plurinacional de Bolivia. Recuperado de http://www.planificacion.gob.bo/

Resolución de la Asamblea General de Naciones Unidas. (2010). (A/RES/64/292), 28 de julio.

Rosales, G. (2011). Las relaciones chileno-bolivianas durante los gobiernos de la Concertación en Chile. Tesina de grado para la Licenciatura en Relaciones Internacionales, Facultad de Ciencia Política y Relaciones Internacionales, Universidad Nacional de Rosario, Rosario, Argentina.

Sanjinés, R. (2007). 25 años de vigencia democrática, Vol. 1. La Paz, Bolivia: Editorial La Razón.

Tokatlián, J. (1997). Condicionalidad y drogas: el caso de Colombia. Colombia Internacional 44, 4-9.

Trejos, L. (2012). Ejes articuladores del discurso internacional del Presidente del Estado Plurinacional de Bolivia, Evo Morales Ayma. Encrucijada Americana 5 (2), 43-53.

Última Hora. (3 de julio de 2013). EE.UU. niega responsabilidad en el bloqueo a vuelo de Morales.

Van Klaveren, A. (1992). Entendiendo las políticas exteriores latinoamericanas: modelo para armar. Estudios Internacionales 25 (98), 169-216.

Zuleta, J. (26 de julio de 2011). Litio, gas natural y China. Bolpress. 